\title{
Facile Synthesis of Ultrahigh-Surface-Area Hollow Carbon Nanospheres and their Application in Lithium-Sulfur Batteries
}

\author{
S. Zeng, Y. Yao, L. Huang, H. Wu, B. Peng, Q. Zhang, X. Li, L. Yu, S. Liu, W. Tu, T. Lan, \\ X. Zeng, J. Zou
}

\begin{abstract}
Hollow carbon nanospheres (HCNs) with specific surface areas up to $2949 \mathrm{~m}^{2} \mathrm{~g}^{-1}$ and pore volume up to $2.9 \mathrm{~cm}^{3} \mathrm{~g}^{-1}$ were successfully synthesized from polyaniline-co-polypyrrole hollow nanospheres by carbonization and $\mathrm{CO}_{2}$ activation. The cavity diameter and wall thickness of HCNs can be easily controlled by activation time. Owing to their large inner cavity and enclosed structure, HCNs are desirable carriers for encapsulating sulfur. To better understand the effects of pore characteristics and sulfur contents on the performances of lithium-sulfur batteries, three composites of HCNs and sulfur are prepared and studied in detail. The composites of HCNs with moderate specific surface areas and suitable sulfur content present a better performance. The first discharge capacity of this composite reaches $1401 \mathrm{mAh} \mathrm{g}^{-1}$ at $0.2 \mathrm{C}$. Even after 200 cycles, the discharge capacity remains at $626 \mathrm{mAh} \mathrm{g}^{-1}$.
\end{abstract}

\section{Introduction}

Porous carbon materials have been widely used in many fields because of their high conductivity, high specific surface area (SSAs), low cost, and easy availability. In particular, they have been applied as electrode host materials in energy storage devices. To better accommodate the active materials, porous carbon materials have been made into various morphologies such as carbon sphere, carbon nanotube, carbon nanosheet, 3D porous carbon, and other forms.1-6 Among various morphologies of carbon materials, carbon nanospheres (CNS) have attracted much academic and industrial attention due to their regular geometry, good liquidity, tunable porosity, and controllable particle size distribution. ${ }^{-2}$ Compared with CNS, hollow carbon nanospheres (HCNs) have larger internal cavities which provide a unique storage space or relatively closed reaction environment. 10,11 The SSAs and pore volume of HCNs are significantly important because they affect the loading of other objects. However, the previous reports have shown that direct carbonization of precursors can hardly obtain carbon nanospheres with high SSAs $\left(>1500 \mathrm{~m}^{2} \mathrm{~g}^{-1}\right)$. 2 -15 Surprisingly, Xu et al. report a facile method to obtain ultrahigh-surface-area $\mathrm{HCNs}$ by simple carbonization of polyaniline-copolypyrrole (PACP) hollow spheres without tedious templating and activation procedures.16 According to this work, we tried to repeat the synthesis of HCNs with high SSAs but unfortunately were not successful. Most SSAs of obtained HCNs are very low and close to the results $\left(610 \mathrm{~m}^{2} \mathrm{~g}^{-1}\right)$ of Ref. $\frac{12}{2}$, except for one sample that is prepared by carbonizing a small amount of PACP $(0.5 \mathrm{~g})$. This sample has a carbon yield of $4 \%$, which is much lower than the yields of other samples $(20 \approx 30 \%)$. Combining all these results, we deduce that the direct carbonization of PACP could only prepare HCNs with low SSAs and the reported ultrahigh surface area of HCNs is a result of activation by traces of water, $\mathrm{CO}_{2}$, and $\mathrm{O}_{2}$. Actually, these components can hardly be completely removed before carbonization. Moreover, the 
carbonizations of PACP will produce water and $\mathrm{CO}_{2}$ that will remain in the furnace for quite a time. Because the contents of these components are very low, the activation method reported by $\mathrm{Xu}$ et a.l needs a long time $(\approx 6-20 \mathrm{~h})$ and high temperature $\left(\approx 900-1000^{\circ} \mathrm{C}\right)$ to synthesize HCNs with high SSAs. In addition, the ratio of activator to PACP is affected by the ratio of the volume of furnace hearth to the mass of PACP and the clean degree of the furnace hearth, which results in the uncontrollability and non-universality of this method. Accordingly, activation is needed to synthesize HCNs with high SSAs. Among various activation methods, $\mathrm{CO}_{2}$ activation is a relatively mild process that could partially retain the nanostructure of the raw materials. Therefore, we used $\mathrm{CO}_{2}$ activation to increase the surface area of HCNs.

It is known that elemental sulfur exhibits a high theoretical capacity $\left(1675 \mathrm{mAh} \mathrm{g}^{-1}\right)$ and energy density $\left(2567 \mathrm{Wh} \mathrm{kg}^{-1}\right)$, which are much higher than those of conventional inorganic metalbased lithium-ion batteries. $.17-21$ Moreover, sulfur as a cathode material also has other advantages such as low cost and environmentally friendliness. However, Li-S batteries suffer from some major problems that include poor conductivity of sulfur $\left(5 \times 10^{-30} \mathrm{~S} \mathrm{~cm}^{-1}\right)$ and discharge product $\mathrm{Li}_{2} \mathrm{~S}$, serious dissolution of intermediate polysulfides with a shuttling effect, and volumetric expansion $(76 \%)$ in the discharge processes. $\frac{17}{22}-25$ These problems result in low specific discharge capacity, poor cyclability, severe self-charge and deteriorated rate capability. $\underline{26}-28$ It is therefore desirable to design new materials with high sulfur contents, high specific capacity, and good cycle performance. One of the most widely adopted approaches is to encapsulate sulfur within porous carbon because of its high conductivity, high surface area, and pore volume. Among various porous carbons, HCNs with high SSAs are ideal carriers for loading sulfur because the stable carbon shells have good elasticity to effectively accommodate the strain of volume change during extraction-insertion of lithium ions and provide relatively closed reaction environment for sulfur converting into polysulfide lithium. $\underline{29}$ Therefore, three composites of HCNs and sulfur are prepared and studied in detail. The composites of HCNs with moderate SSAs and low sulfur content show an initial discharge capacity of $1401 \mathrm{mAh} \mathrm{g}^{-1}$ at $0.2 \mathrm{C}$. Even after 200 cycles, the discharge capacity remains at $626 \mathrm{mAh} \mathrm{g}^{-1}$.

\section{Results and Discussion}

As illustrated in Figure $\underline{1}$, ultrahigh SSAs hollow carbon nanospheres are synthesized through a facile polymerization of aniline and pyrrole mixture, followed by calcination of the resultant PACPs and an activation process. Firstly, the PACP were obtained by solution polymerization. The mechanism of forming hollow PACP structure has been discussed in Ref. 30 . Secondly, the formed PACP is carbonized at $800^{\circ} \mathrm{C}$ leading to the formation of HCNs. HCNs hollow structure is maintained due to the robust conjugated structure of PACP. Finally, the ultrahigh specific surface $\mathrm{HCNs}-\mathrm{AC}$ were obtained by activating the $\mathrm{HCNs}$ with $\mathrm{CO}_{2}$ at $950{ }^{\circ} \mathrm{C}$. Additionally, the structural parameters of HCNs, such as the carbon shell, SSAs, inner and 
outer diameters, etc. can be tuned by changing the activation time at a constant flow rate of $\mathrm{CO}_{2}$.

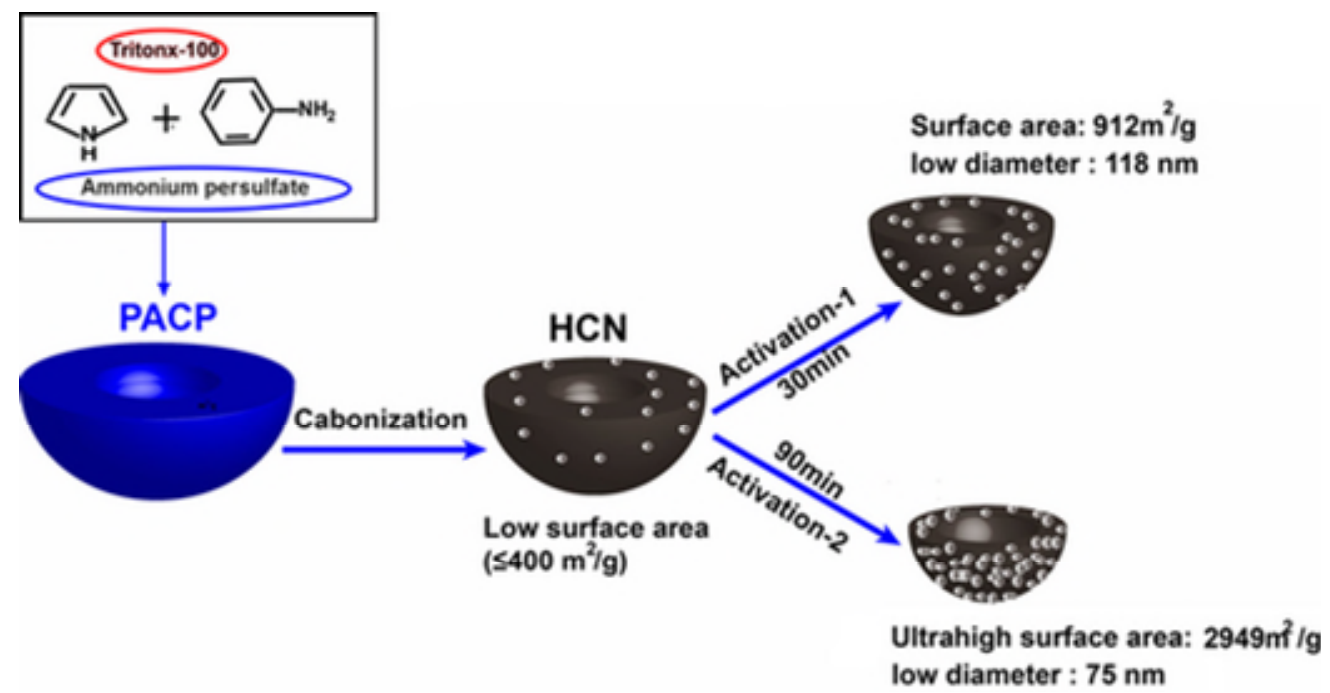

Figure 1 Schematic illustration of formation process of HCNs-AC

The morphologies of PACP, HCNs, and HCNs-AC were investigated by SEM and TEM. As shown in Figure $\underline{2}$ a, a PACP spherical structure with a diameter of about $137 \mathrm{~nm}$ was obtained and its internal hollow structure was further observed by the TEM pattern (Figure $\underline{2} b$ ). The SEM images of the HCNs are exhibited in Figure $\underline{2}$ c. Obviously, HCNs consist of spherical particles similar to PACP, when it was carbonized at $800^{\circ} \mathrm{C}$. Comparing with PACP, HCNs diameter was reduced. Moreover, HCNs show relatively low SSAs (119 $\mathrm{m}^{2} \mathrm{~g}^{-1}$, Figure S1 in Supporting Information). Thus, it must be noted that a single carbonization process cannot obtain HCNs with high specific surface areas just by controlling the carbonization temperature and times. As we know, metal organic frameworks (MOFs) are often used as precursors to obtain high SAAs carbon materials due to their high SSAs (up to $10000 \mathrm{~m}^{2} \mathrm{~g}^{-1}$ ). 31 , 32 Actually, direct carbonization of MOFs can hardly produce the carbonaceous materials with SSAs greater than $2000 \mathrm{~m}^{2} \mathrm{~g}^{-1}$. Only by post-treatment of the carbonized product one can obtain ultrahigh SSAs $\left(>2000 \mathrm{~m}^{2} \mathrm{~g}^{-1}\right), \underline{33}, \underline{34}$ It is impossible to obtain HCNs with ultrahigh SSAs by direct carbonization of PACP. In addition, carbon yields as low as $4 \%$ c resulted from the direct carbonization process without the activation of water, $\mathrm{CO}_{2}$, and $\mathrm{O}_{2}$. As shown in Figure $\mathrm{S} 1$, the carbon yield maintains at about $20 \%$, no matter how the carbonization temperature changes. Moreover, the average diameter of all HCNs is similar (Figure S2). $\mathrm{N}_{2}$ adsorptiondesorption isotherm of HCNs under different carbonization conditions are shown in Figure S3. All $\mathrm{N}_{2}$ adsorption-desorption isotherms indicate a distinct hysteresis loop, that is, a gap between the adsorption branch and the desorption branch. These phenomena strongly indicate the 
presence of mesopores. $\frac{35}{}$ The SSAs were calculated based on the BET algorithm. All samples of normal carbonization show a low SSA $\left(<401 \mathrm{~m}^{2} \mathrm{~g}^{-1}\right)$. In other words, the total amount of carbon is not consumed in the carbonization process. However, the HCN-800-20H-10R, obtained by carbonizing $0.5 \mathrm{~g}$ of PACP, shows an ultrahigh-surface-area $\left(>2800 \mathrm{~m}^{2} \mathrm{~g}^{-1}\right)$. But the carbon yield is as low as $4 \%$, which is much less than the average yields (20\%). Thus, we attributed the ultrahigh SSAs to the slow activation by trace amounts of water, $\mathrm{CO}_{2}$, and $\mathrm{O}_{2}$. Among various activation methods, $\mathrm{CO}_{2}$ activation is a relatively mild process that could partially retain the nanostructure of the raw materials. $\frac{36}{6}$ Therefore, we used $\mathrm{CO}_{2}$ activation to increase the surface area of HCNs. As shown in Figure $\underline{\mathbf{2}} \mathrm{d}$, the average diameter of HCNs-AC is smaller than HCNs and PACP. The TEM images(Figure $\underline{2}$ e)demonstrate the hollow spherical structure of $\mathrm{HCNs}-\mathrm{AC}$. In detail, the $\mathrm{HCNs}$ activated under a $\mathrm{CO}_{2}$ flow for $\approx 30-90$ min generating a different quantity of pores and different SSAs by following chemical reaction [Eq. 1]:

$$
\mathrm{C}+\mathrm{CO}_{2}=2 \mathrm{CO}
$$
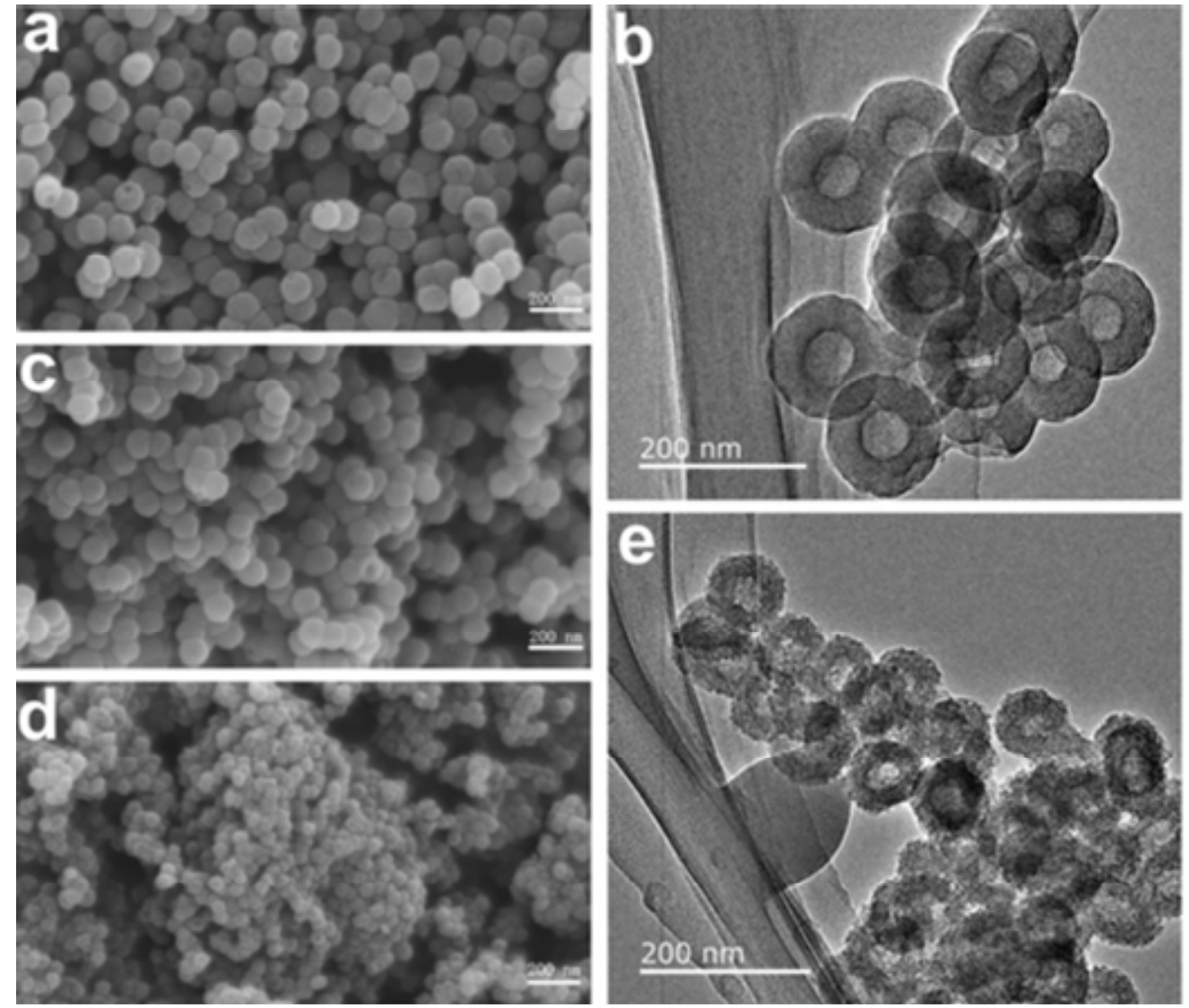

Figure 2 The images of (a,b) PACP, (c) HCN-800-2H10R, (d, e) HCNs-AC90; (a, c, d - SEM, b, e TEM). All scale-bars are $200 \mathrm{~nm}$. 
Remarkably, not all activation conditions can lead to hollow carbon spheres with ultrahigh SSAs. Xu et al. illustrated that the $\mathrm{KOH}$ activation cannot result in hollow carbon spheres due to non-uniform activation, as well as uncontrollability.16 As shown in Figure S4, the outer diameter of hollow spheres was reduced from 137 to $75 \mathrm{~nm}$ and the inner diameter from 52 to $33 \mathrm{~nm}$ for PACP and HCNs-90, respectively. Moreover, the wall thickness of HCNs-AC90 was drastically decreased from $85 \mathrm{~nm}$ for PACP to $42 \mathrm{~nm}$.

To get a further understanding of the structure of the as-prepared PACP, HCNs, and HCNsAC, XRD and Raman spectroscopy were performed. Figure $\underline{\mathbf{3}}$ a shows the XRD patterns of PACP that well match with the results of Ref. $\underline{30}$. After carbonization, two characteristic peaks at $24^{\circ}$ and $44^{\circ}(2 \theta)$ were observed for HCNs and HCNs-AC30, which correspond to carbon $\left(\begin{array}{lll}0 & 0 & 2\end{array}\right)$ and $\left(\begin{array}{lll}1 & 0 & 1\end{array}\right)$ planes, respectively. The HCNs has a relatively high $\left(\begin{array}{lll}0 & 0 & 2\end{array}\right)$ peak intensity compared to that of HCNs-AC30, indicating a higher degree of graphitization in HCNs than in HCNs-AC30. $\underline{37}^{7}$ Raman spectra of these samples in Figure $\underline{3} \mathbf{b}$ further confirm this result. HCNsAC, especially HCNs-AC90, has a higher D band and lower G band than the non-activated HCNs. The peaks of the $D$ and $G$ bands are centered at $\approx 1364.91$ and $\approx 1588.67 \mathrm{~cm}^{-1}$, respectively. The $\mathrm{D}$ band is related to the double-resonance Raman process in disordered carbon. .48 The intensity of the $\mathrm{D}$ band depends on the uniformity of the disordered carbon. .11 The intensity of $\mathrm{G}$ band is determined by the graphitic carbon phase. ${ }^{42} \mathrm{In}$ order to more accurately characterize the disorder degree of these materials, the ratios of the $I_{\mathrm{D}} / I_{\mathrm{G}}$ of $\mathrm{HCN}$, HCNs-AC30, HCNs-AC60, and HCNs-90 were calculated to be 0.95, 1.00, 1.02, and 1.14, respectively. These data show that disordered carbon was formed and increased with the increase of activation time. In particular, a high $I_{\mathrm{D}} / I_{\mathrm{G}}$ ratio of HCNs-AC90 indicates the generation of a large number of defects, resulting in the presence of numerous pores. Figure $\underline{\mathbf{3}} \mathrm{c}$ further proved the existence of these pores. Figure $\underline{\mathbf{3}} \mathrm{c}$ shows the $\mathrm{N}_{2}$ adsorption-desorption isotherm curves for PACP, HCNs, and HCNs-AC prepared by different activation times (30, 60 , and $90 \mathrm{~min}$ ). It can be seen that the HCNs-AC90 exhibits the highest $\mathrm{N}_{2}$ adsorptions in all samples, demonstrating the highest pore volume (up to $2.9 \mathrm{~cm}^{3} \mathrm{~g}^{-1}$ ). Moreover, HCNs-AC90 has more mesopores than other samples, due to its more obvious hysteresis effect at a high relative pressure ranging from 0.5 to 0.99 in $\mathrm{N}_{2}$ adsorption-desorption $\underline{43}$, 44 The pore size distributions of PACP, HCN, and HCNs-AC are shown in Figure $\underline{\mathbf{3}}$ d. HCNs-AC90 shows a large number of mesopores compared with other materials. HCNs-AC30 is mainly microporous owing to insufficient activation (30 min). These results indicate that the activation times has a significant effect on the SSAs, the nanostructure, and the degree of graphitization of HCNs-AC. 

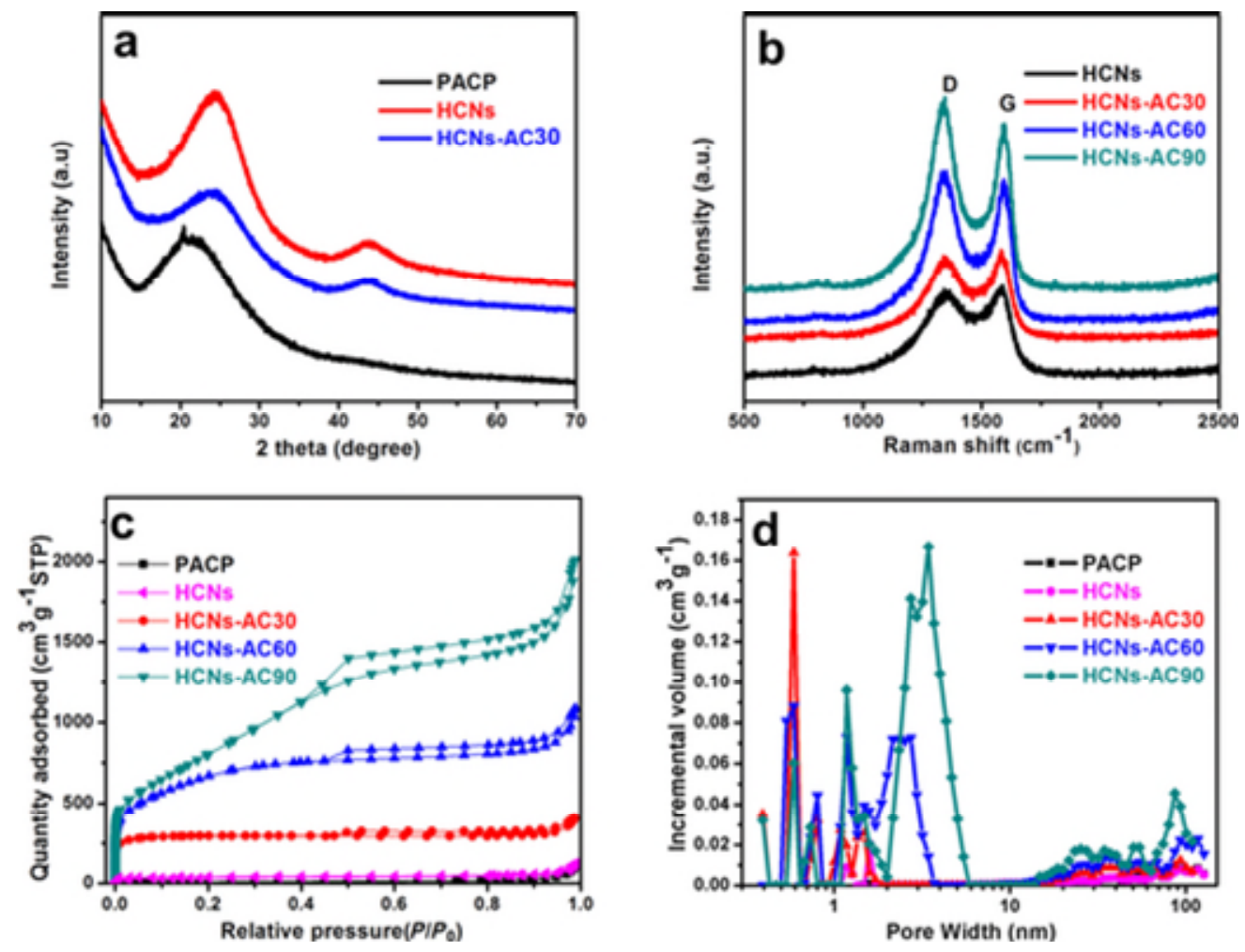

Figure 3 (a) X-ray diffraction patterns of PACP, HCNs and HCNs-AC30. (b) Raman patterns for HCNs and HCNs-AC prepared by different activation time (30, 60 and $90 \mathrm{~min}$ ). (c) $\mathrm{N}_{2}$ adsorption-desorption isotherms and (d) pore size distribution of PACP, HCNs and HCNs-

AC with different activation time (30,60 and $90 \mathrm{~min})$.

Figure 4presents the SEM images and the outer diameter distributions of HCNs-AC prepared by different activation time. It can be clearly seen that the average outward diameter of HCNs-AC decreases gradually with increasing activation time. As the activation time is prolonged, the carbon yields of HCNs-AC30, HCNs-AC60 and HCNs-AC90 are 25, 12.9, and 5\%, respectively (Table. S1). The outer diameter distributions of HCNs-AC30, HCNs-AC60, and HCNs-AC90 are presented in Figure $\underline{4} \mathrm{~b}, \mathrm{~d}$, and $\mathrm{f}$, respectively. When the activation time is 30 minutes, the HCNs-AC average outer diameter is $118 \mathrm{~nm}$ and SSAs is $912 \mathrm{~m}^{2} \mathrm{~g}^{-1}$. In contrast, when activation time is 90 minutes, the HCNsAC average outer diameter drastically reduced to $76 \mathrm{~nm}$ and SSAs is up to $2949 \mathrm{~m}^{2} \mathrm{~g}^{-1}$. Thus, the activation time can play a dual role in controlling the HCNs-AC particle size and SSAs. 

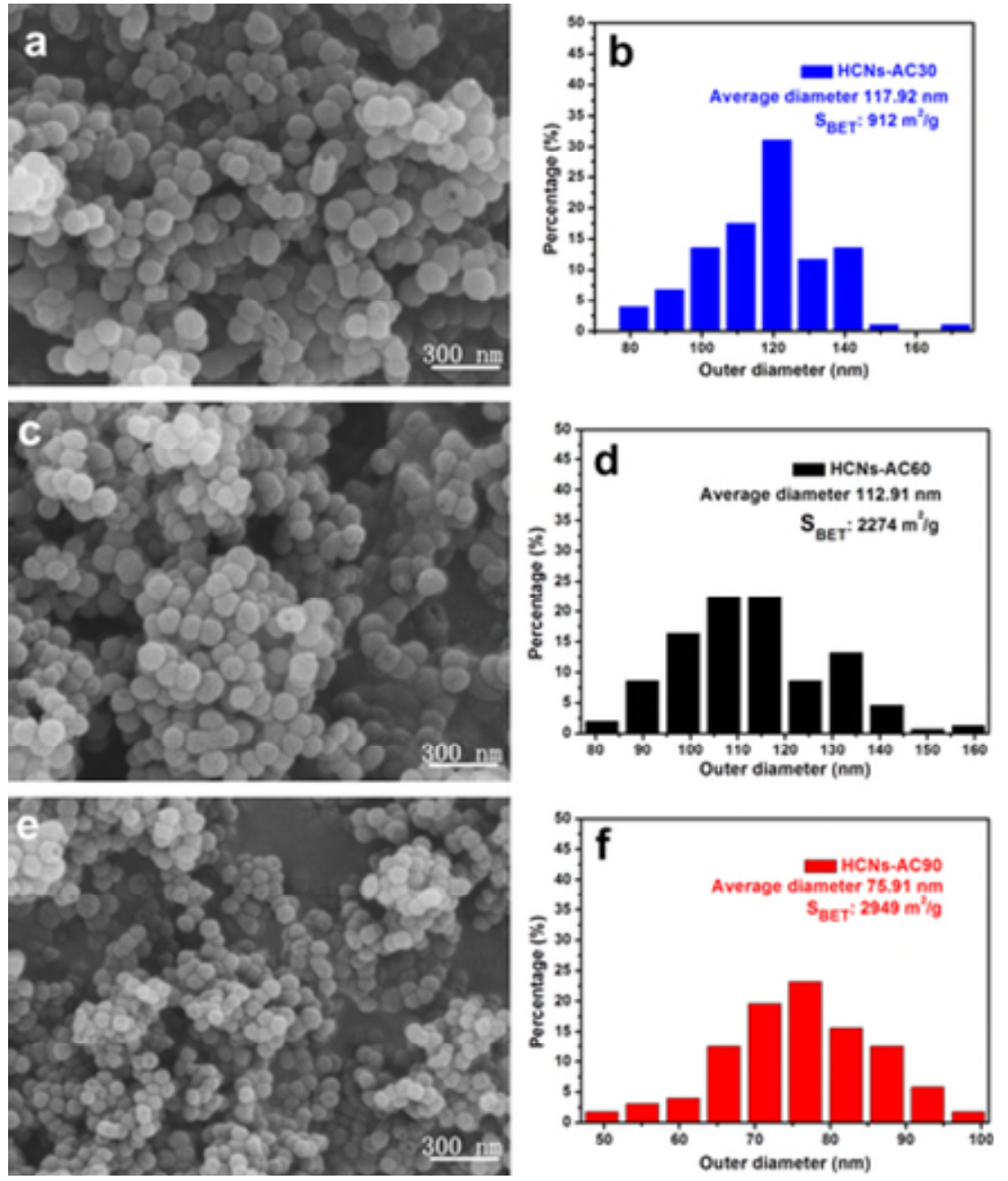

Figure 4 SEM images of (a) HCNs-AC30 (c) HCNs-AC60 (e) HCNs-AC90; (b, d, f) outer diameter distribution histograms and SSAs of HCNs-AC with different activation time (30,60 and $90 \mathrm{~min})$ from analysis of SEM.

The application of HCNs-AC as a cathode host material was investigated in Li-S batteries. HCNs-AC with different SSAs were selected and the cathodes with different sulfur contents were prepared by using a melt-diffusion method. As shown in Figure $\underline{\mathbf{5}}$ a, after loading $60 \%$ sulfur, the diameter of HCNsAC60/S-60 changed little as compared with HCNs-AC60. However, when the sulfur content increased to $75 \%$, the diameter of HCNs-AC60/S-75 was drastically increased and a lot of sulfur particles were attached on the outside of the HCNs-AC-60/S-75 (Figure $\underline{\mathbf{5}} \mathrm{c}$ ). This is mainly due to the fact that the small pore volume $\left(1.59 \mathrm{~cm}^{3} \mathrm{~g}^{-1}\right)$ and limited cavity cannot load $75 \%$ sulfur content, which results in the residual sulfur attached on the carbon sphere surface. In contrast, HCNs-AC90 (Figure $\underline{\mathbf{5}} \mathrm{e}$ ) can effectively encapsulate such high sulfur content because of its high pore volume (up to $2.9 \mathrm{~cm}^{3} \mathrm{~g}^{-1}$ ) and ultrahigh SSAs $\left(2949 \mathrm{~m}^{2} \mathrm{~g}^{-1}\right)$. Figure $\underline{\mathbf{5}} \mathrm{b}$, d, and $\mathrm{f}$ present the TGA curves of the HCNs-AC/sulfur composites (HCNs-AC60/S-60, HCNs-AC60/S-75, and HCNs-AC90/S-75). Obviously, the sulfur contents of these samples are consistent with our design. 

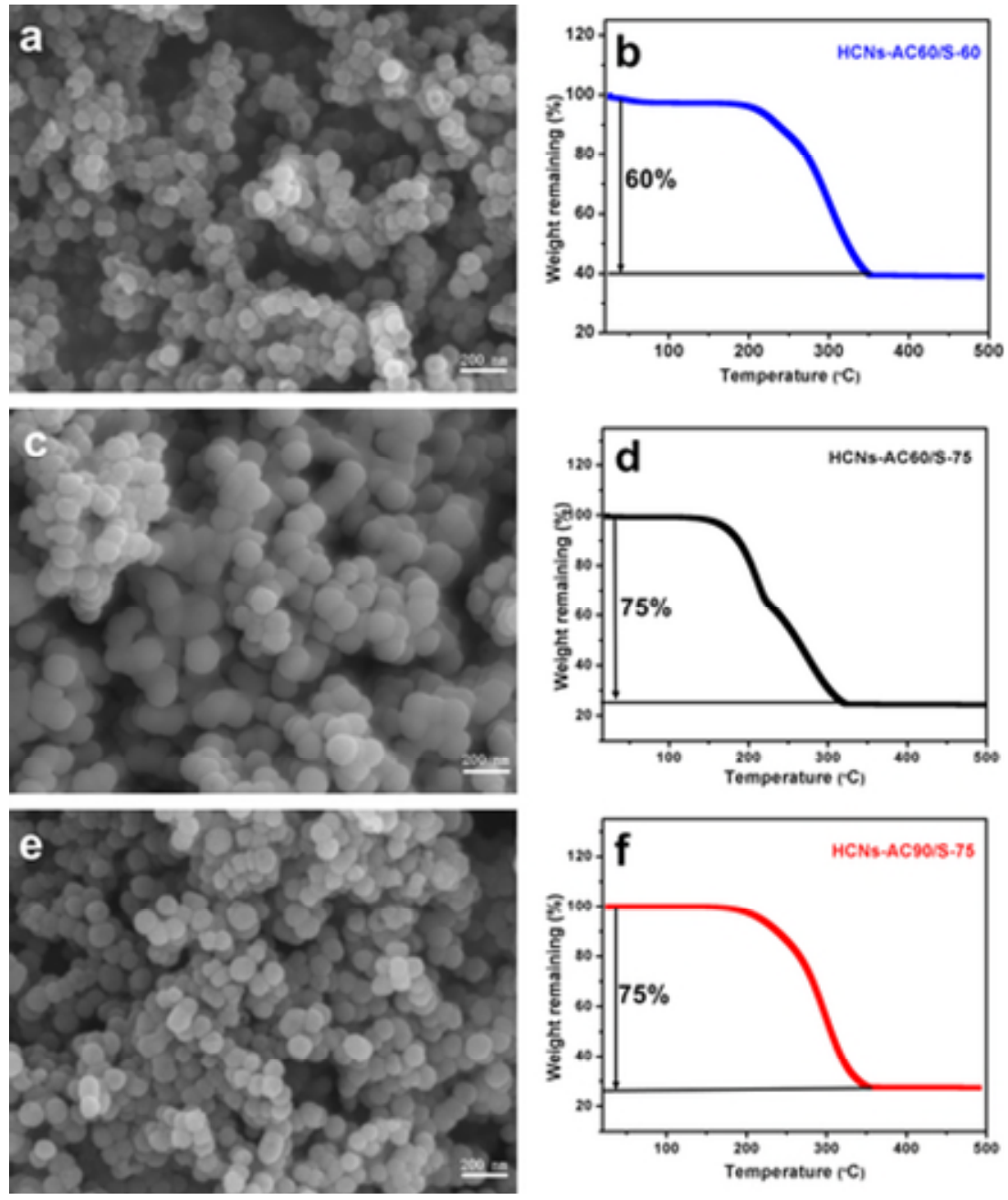

Figure 5 SEM images for HCNs-AC/sulfur composites (a) HCNS-AC60/S-60, (c) HCNs-AC60/S-75 and (e) HCNs-AC90/S-75; Thermogravimetric analysis (TGA) of (b) HCNs-AC60/S-60, (d) HCNsAC60/S-75, and (f) HCNs-AC90/S-75.

The elemental maps of HCNs-AC60/S-60 (Figure ㅁ), HCNs-AC60/S-60 (Figure S5) and HCNsAC60/S-60 (Figure S5) indicate the homogeneous distribution of carbon (Figure $\underline{\mathbf{6}} \mathrm{c}$ and Figure S5 g, h) and sulfur (Figure $\underline{\mathbf{6}} \mathrm{d}$ and Figure S5 e,f) in these samples. Moreover, we can observe (Figure S6) that the prepared electrode film shows a flat electrode surface and the thickness is about $40 \mu \mathrm{m}$. A nano sized sphere structure is attributed to obtaining a flat electrode surface. 

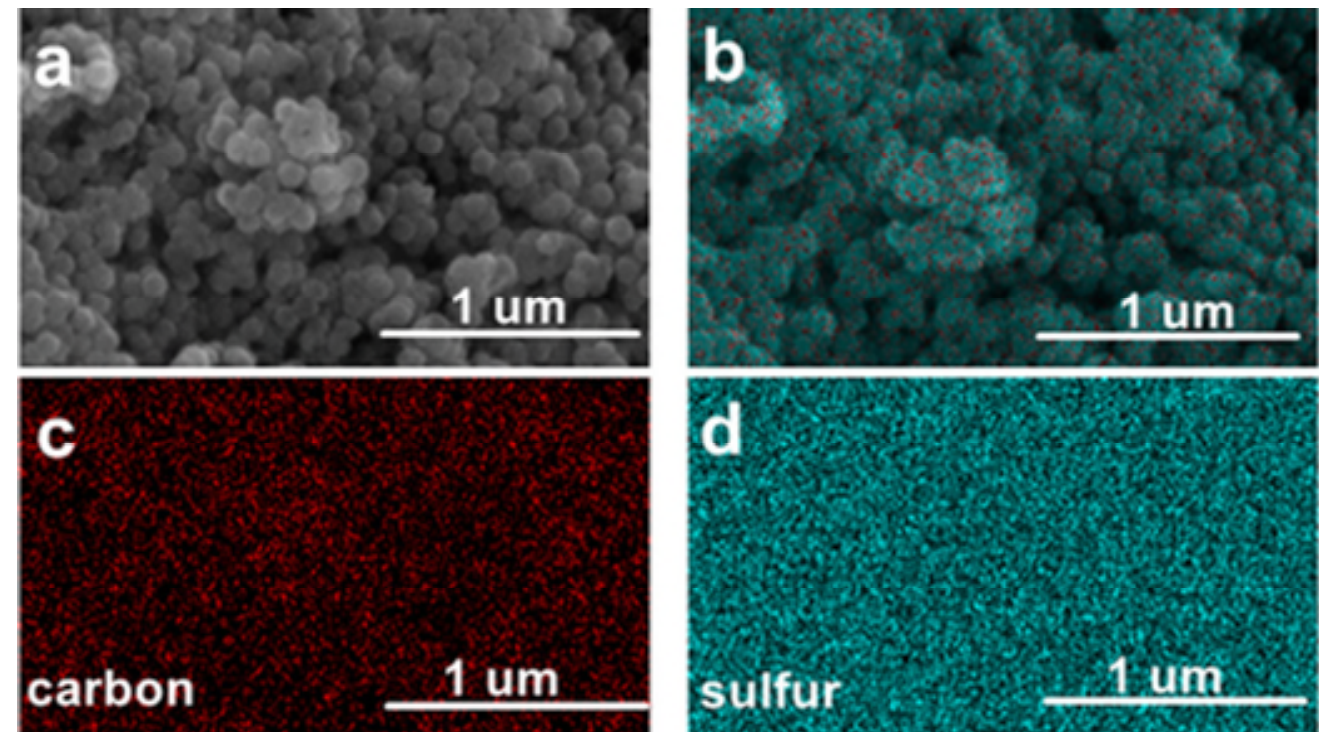

Figure 6 SEM image of (a) HCNs-AC60/S-60 and the corresponding EDS elemental maps for (b) all elements combined, (c) carbon, and (d) sulfur.

Raman spectra were used to characterize the structures of HCNs-AC, elemental sulfur, and various HCNs-AC/S composites (Figure $\underline{\mathbf{7}}$ a). Sulfur shows several typical Raman peaks which can be assigned to the $\mathrm{S}-\mathrm{S}$ bond. ${ }^{45}$ However, no signal of sulfur was found below $500 \mathrm{~cm}^{-1}$ in all HCNs-AC/S samples, indicating that sulfur is embedded into the pores of HCNs-AC. Figure $\underline{7} b$ exhibits the XRD patterns of HCNs-AC, elemental sulfur, and various HCNs-AC/S composites. The low intensity and broadened peak is a typical feature of amorphous carbon in the HCNs-AC samples. In contrast, the pure elemental sulfur has well-defined diffraction peaks, corresponding to an orthorhombic structure. 46 Only very tiny characteristic diffraction peaks corresponding to bulk crystalline sulfur can be detected in all HCNsAC/S samples, except for the HCNs-AC60/S-75 (curves in Figure $\underline{7}$ b), which indicates high dispersion of amorphous sulfur in HCNs-AC. $\underline{23}$ The obvious diffraction peaks corresponding to bulk crystalline sulfur appeared in the XRD curve of HCNs-AC60/S-75 sample, which suggests the existence of excess crystalline sulfur on the external surface of HCNs-AC60. Thus, HCNs-AC60/S-60 and HCNs-AC90/S75 can obtain better sulfur encapsulation. Figure $\underline{7} \mathrm{c}$ shows XPS survey spectra of the HCNs-AC/S composites. In the XPS survey spectra of $\mathrm{HCNs}-\mathrm{AC} / \mathrm{S}$, four peaks centering at $\approx 163.5, \approx 284.6, \approx 400.0$, and $\approx 532.0 \mathrm{eV}$, corresponding to $\mathrm{S} 2 \mathrm{p}, \mathrm{C} 1 \mathrm{~s}, \mathrm{~N} 1 \mathrm{~s}$, and $\mathrm{O} 1 \mathrm{~s}$, respectively, can be clearly observed. The elemental contents of N in HCNs-AC60 and HCNs-AC90 are 3.3 and 2.2 at. \%, respectively. And this result proves that over activation leads to the decrease of $\mathrm{N}$ content. In the $\mathrm{S} 2 \mathrm{p}$ spectrum of the HCNsAC60/S-60 (Figure $\underline{7} \mathrm{~d}$ ), the peaks at $\approx 163.6$ and $\approx 164.8 \mathrm{eV}$ represent the $\mathrm{S} 2 \mathrm{p}_{3 / 2}$ and $\mathrm{S} 2 \mathrm{p}_{1 / 2}$ orbitals of elemental sulfur. As shown in Figure $\underline{7} \mathrm{e}-\mathrm{f}$, the $\mathrm{N} 1 \mathrm{~s}$ spectrum is divided into four peaks located at $\approx 398$, $\approx 401, \approx 402$, and $\approx 405 \mathrm{eV}$, which are attributed to pyridinic, pyrrolic, quaternary, and chemisorbed nitrogen, respectively. $\underline{.}, \underline{48}$ The amount of quaternary $\mathrm{N}$ was decreased dramatically with extending the activation time. To date, it has been well recognized that nitrogen doping in the carbon material can effectively improve the chemical adsorption capability of carbon to poly sulfides. ${ }^{49}$ 

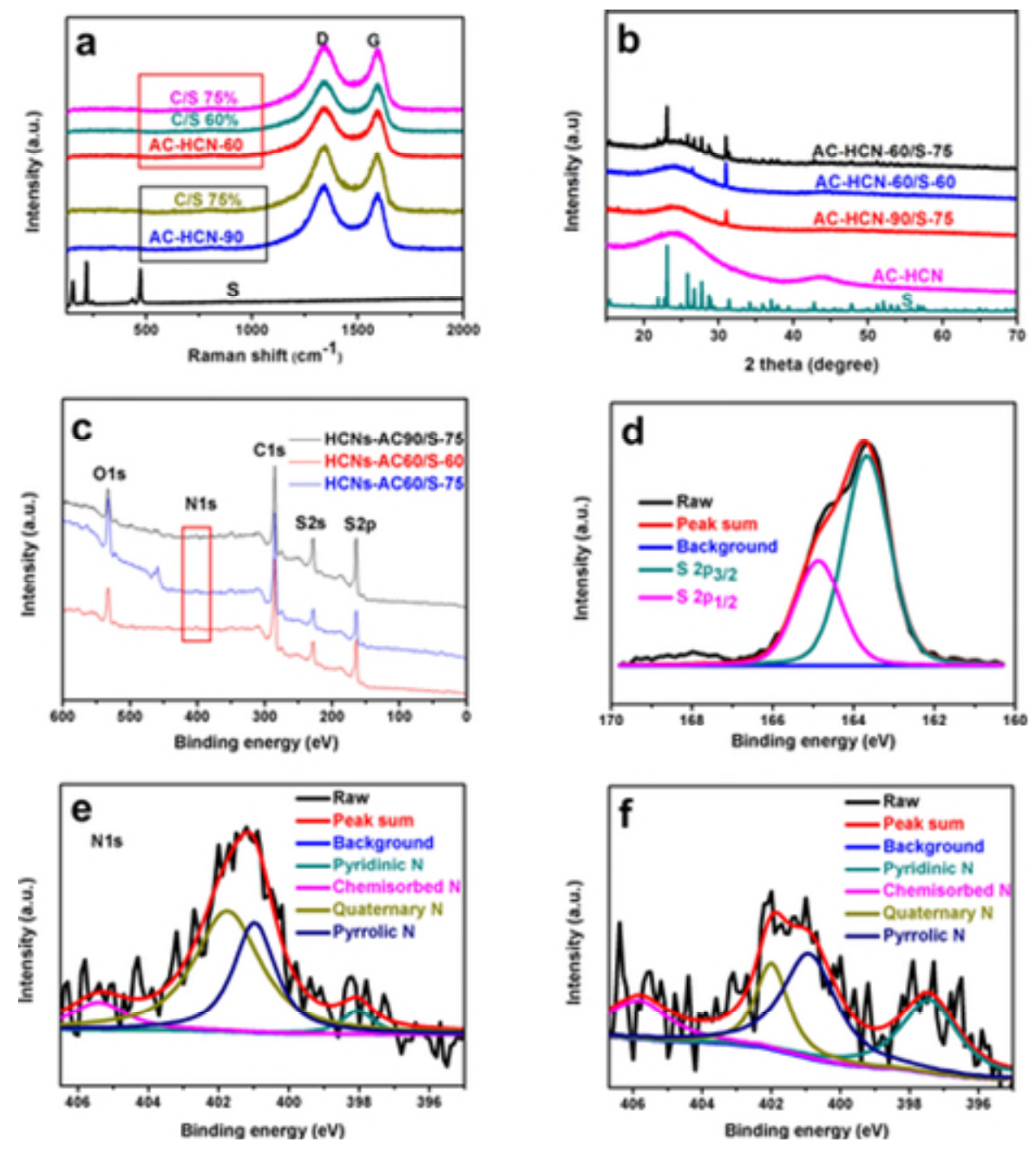

Figure 7 (a) The Raman spectra of pure sulfur, HCNs-AC60, HCNs-AC90, HCNs-AC60/S-60, HCNs-AC60/S-75, and HCNs-AC90/S-75. (b) X-ray diffraction patterns of HCNs-AC, HCNsAC60/S-60, HCNs-AC60/S-75, HCNs-AC90/S-75, and virgin sulfur. (c) The XPS spectra of HCNsAC60/S-60, HCNs-AC60/S-75, and HCNs-AC90/S-75. (d) Resolution spectra of S 2p for HCNsAC60/S-60 (e) Resolution spectra of N 1s for HCNs-AC60/S-60. (f) Resolution spectra of N 1s for HCNs-AC90/S-75.

Coin cells were assembled with a metallic $\mathrm{Li}$ foil as the anode. The electrochemical performance of the HCNs-AC/S nanocomposites was evaluated by cyclic voltammetry (CV), galvanostatic dischargecharge cycling, and electrochemical impedance spectroscopy. Figure $\underline{8}$ a presents the typical CV curves of a cell within the voltage window of 1.6-2.9 V at a scan rate of $0.1 \mathrm{mV} \mathrm{s}^{-1}$. Except for the first cycle, the $\mathrm{CV}$ curves show a complete overlapping of the characteristic cathodic and anodic peaks. The position and intensity of these peaks maintain stable at the subsequent scans, indicating that good electrochemical stability and reversibility. $\underline{50}, \underline{51}$ The reversibility probably resulted from the unique microspherical hollow structure of the HCNs-AC60/S-60 nanocomposite. ${ }^{9}$ Because sulfur undergoes a dissolution-deposition process, the sulfur redistributes in the HCNs during the first discharge-charge cycle, which leads to the right shift of the redox peaks. This also consists with the fact that the plateaus of the second discharge curve are higher than those of the initial cycle. $.52-54$ Figure $\underline{8} b$ displayed the typical galvanostatic charge-discharge voltage curves of the as-prepared AC-HCN-60/S-60 cathode, measured at a current rate of $0.2 \mathrm{C}$. The first time discharge capacity is $1407 \mathrm{mAh} \mathrm{g}^{-1}$, then the discharge 
capacity gradually decays from 1102 (5th) to $795 \mathrm{mAh} \mathrm{g}^{-1}$ at 50 cycles. Even after 100 cycles, the capacity can still maintain about $742 \mathrm{mAh} \mathrm{g}^{-1}$, which corresponds to $66 \%$ of the second discharge capacity $\left(1082 \mathrm{mAh} \mathrm{g}^{-1}\right)$. The capacity decrease of the second cycles could be due to the redistribution of sulfur and the irreversible dissolution of polysulfide into electrolyte. $\underline{55}$
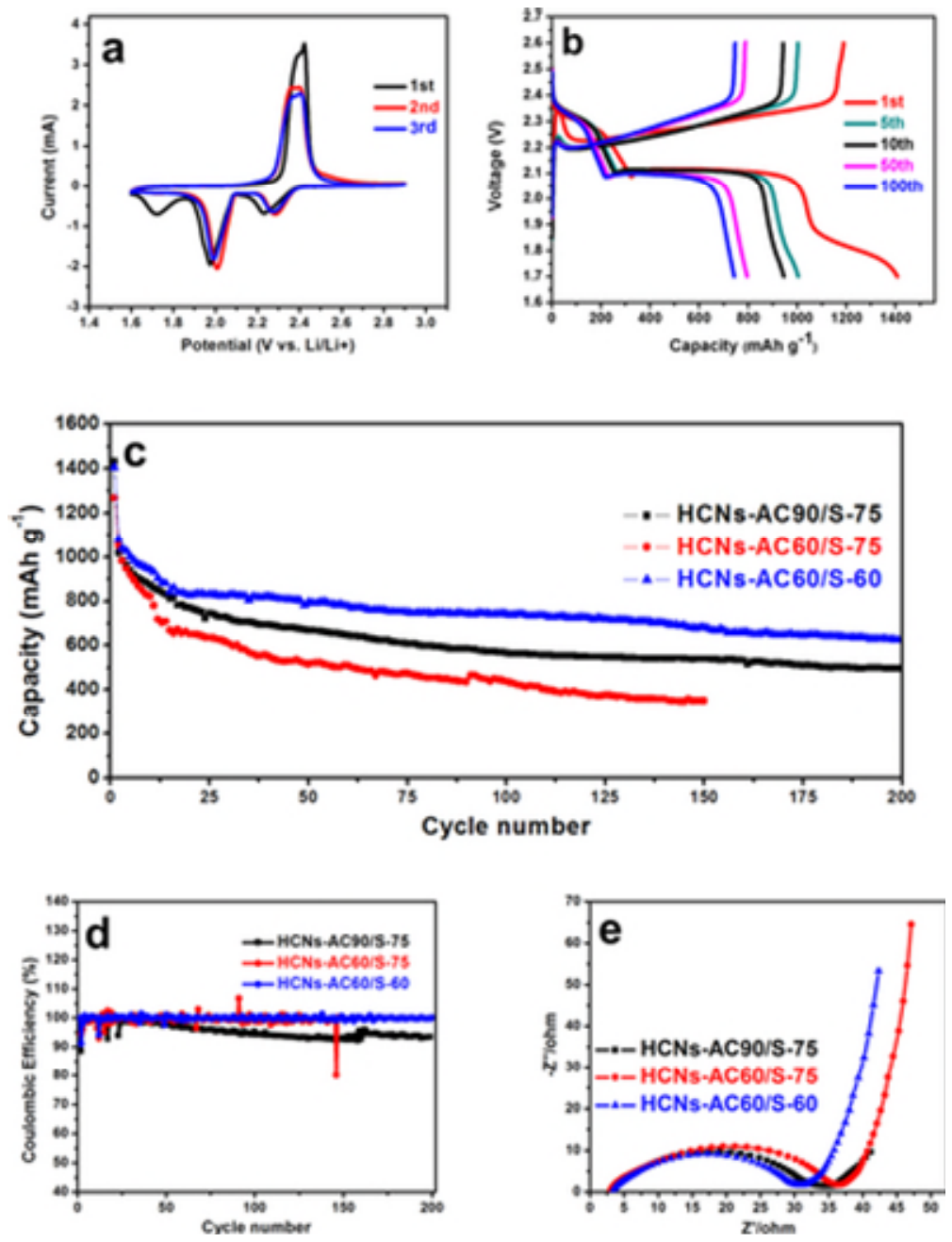

Figure 8 (a) Cyclic voltammetry curves of HCNs-AC60/S-60 cathode. (b) Discharge-charge curves recorded at different cycles for HCNs-AC60/S-60. (c) Discharge capacity of over 200 cycles at $0.2 \mathrm{C}$ after stopping the rate performance test for HCNs-AC60/S-60 and HCNs-AC90/S-75, except for HCNs-AC60/S-75 (150 cycle). (d) Coulombic efficiency of over 200 cycles at $0.2 \mathrm{C}$ corresponding to the Figure $\underline{\mathbf{5}}$ c. (e) Nyquist plots of HCNs-60/S-60, HCNs-AC60/S-75 and HCNs-AC90/S-75.

The effects of sulfur contents and SSAs of HCNs-AC on the performance of Li-S batteries were further studied. When increasing the sulfur content from $60 \%$ to $75 \%$ for HCNs-AC60 $\left(2274 \mathrm{~m}^{2} \mathrm{~g}^{-1}\right)$, the electrochemical performance of HCNs-AC60/S-75 cathodes drastically deteriorates (Figure $\underline{\mathbf{8}} \mathrm{c}$ ). Moreover, when employing higher SSAs HCNs-AC90 $\left(2949 \mathrm{~m}^{2} \mathrm{~g}^{-1}\right)$ mixed with $75 \%$ sulfur, the initial discharge capacity $\left(1431 \mathrm{mAh} \mathrm{g}^{-1}\right)$ is the highest in all samples, but the capacity decays faster than that of HCNs-AC60/s-60. After 200 cycles, the capacity of HCNs-AC90/s-75 is only $497 \mathrm{mAh} \mathrm{g}^{-1}$, less than that of HCNS-60/S-60 (626 
$\mathrm{mAh}^{-1}$ ). For HCNs-AC60/S-75, when the pores of HCNs-AC60 are filled with sulfur, there is no effective fixation point and thereby causes the remaining sulfur to attach to the outer surface of the carbon sphere. After first discharge, the remaining sulfur generated polysulfide can only dissolve in the electrolyte, resulting in the rapid occurrence of the shuttle effect. For HCNs-AC90/S-75, although no significant sulfur attaches on the outer surface (pore volume $2.9 \mathrm{~cm}^{3} \mathrm{~g}^{-1}$, due to its excessive aperture, the polysulfide cannot be effectively absorbed, resulting in an unstable cycle performance. $\underline{56}$ Moreover, a relatively thin shell must be responsible for the consequence. Figure $\underline{\mathbf{8}} \mathrm{d}$ shows coulombic efficiency curve of various HCNs-AC/S. It can be clearly seen that HCNs-AC60/S-60 has a stable coulombic efficiency (close to $100 \%$ ) due to its excellent conductivity, reasonable sulfur content, and closed carbon shell. The coulombic efficiency of HCNs-AC60/S-75 is extremely unstable because overcharged sulfur content results in shuttle effect as illustrated above.

Finally, the electrochemical impedance spectra (EIS) were shown in Figure $\underline{\mathbf{8}}$ e, which consist of a depressed semicircle in high frequency region and a short line in medium frequency region. The small semicircle indicates a lower charge-transfer resistance. $\underline{57}-59$ The radiuses of the semicircles of HCNs-AC60/S-60 composites are all smaller than others HCNs/S composite, which indicate that HCNs-AC60/S-60 has a much higher electronic conductivity.60, 61 This further demonstrates the excellent performance of HCNs-AC60/S-60 in Li-S batteries. Moreover, compared to the previous reported hollow carbon materials (Table $\underline{1}$.), we obtained HCNs that shows good performance. $\underline{62-67}$

Table 1. Comparisons of properties of HCNs with other hollow carbon materials.

\begin{tabular}{|cccccccc|}
\hline Sample & $\begin{array}{c}\mathbf{S}_{\text {BET }} \\
{\left[\mathbf{m}^{2} \mathbf{g}^{-1}\right]}\end{array}$ & $\begin{array}{c}\text { Sulfur } \\
\text { content } \\
{\left[\mathbf{m g ~ c m} \mathbf{~ c m}^{-2}\right]}\end{array}$ & $\begin{array}{c}\text { Cycle } \\
\text { current }\end{array}$ & First & $\begin{array}{c}\text { Cycle } \\
\text { times }\end{array}$ & $\begin{array}{c}\text { Capacity } \\
\text { maintain }\end{array}$ & ref \\
\hline $\begin{array}{c}\text { Carbon hollow } \\
\text { sphere }\end{array}$ & 1124 & - & $1 \mathrm{C}$ & 1080 & 300 & 780 & 62 \\
$\begin{array}{c}\text { Carbon hollow } \\
\text { sphere/graphene }\end{array}$ & 832 & $1.3-1.7$ & $1 \mathrm{C}$ & 832 & 200 & 575 & 63 \\
$\begin{array}{c}\text { Porous carbon } \\
\text { sphere }\end{array}$ & 1563 & - & $0.5 \mathrm{C}$ & 1258 & 200 & 560 & 64 \\
\hline
\end{tabular}




\begin{tabular}{|c|c|c|c|c|c|c|c|}
\hline Sample & $\begin{array}{c}S_{\text {BET }} \\
{\left[\mathbf{m}^{2} \mathbf{g}^{-1}\right]}\end{array}$ & $\begin{array}{c}\text { Sulfur } \\
\text { content } \\
{\left[\mathrm{mg} \mathrm{cm}^{-2}\right]}\end{array}$ & $\begin{array}{c}\text { Cycle } \\
\text { current }\end{array}$ & $\begin{array}{c}\text { First } \\
\text { capacity }\end{array}$ & $\begin{array}{l}\text { Cycle } \\
\text { times }\end{array}$ & $\begin{array}{l}\text { Capacity } \\
\text { maintain }\end{array}$ & ref \\
\hline $\begin{array}{l}\text { CNT/graphene } \\
\text { nanospheres }\end{array}$ & 979 & 1.1 & $0.5 \mathrm{C}$ & 827 & 500 & $89 \%$ & 65 \\
\hline $\begin{array}{l}\text { Carbon hollow } \\
\text { sphere/ graphene }\end{array}$ & 807 & 3.9 & $0.5 \mathrm{C}$ & 1360 & 200 & 520 & 66 \\
\hline $\begin{array}{l}\text { Hollow carbon } \\
\text { nanorods }\end{array}$ & 218 & 0.37 & $0.5 \mathrm{C}$ & 971 & 100 & 708 & 67 \\
\hline $\begin{array}{l}\text { Hollow carbon } \\
\text { nanospheres }\end{array}$ & 2274 & $1.5-2.0$ & $0.2 \mathrm{C}$ & 1401 & 200 & 626 & $\begin{array}{l}\text { Our } \\
\text { work }\end{array}$ \\
\hline
\end{tabular}

\section{Conclusion}

In summary, we have successfully fabricated the ultrahigh-surface-areas $\left(2949 \mathrm{~m}^{2} \mathrm{~g}^{-1}\right)$ hollow carbon nanospheres (HCNs) by facile carbonization and activation. The pore structure, SSAs, and cavity diameter of HCNs can be easily controlled by tuning the activation time. The high SSAs (2274 $\left.\mathrm{m}^{2} \mathrm{~g}^{-1}\right)$, stable hollow sphere structure, as well as the large pore volume (1.6 $\mathrm{cm}^{3} \mathrm{~g}^{-1}$ ) render HCNs-AC60 as an excellent sulfur host material for high energy Li-S batteries. This leads to an initial discharge capacity of $1401 \mathrm{mAh} \mathrm{g}^{-1}$ and a stable cycle performance ( $626 \mathrm{mAh} \mathrm{g}^{-1}$ even after 200 cycles). The present work not only provides a facile method of producing hollow carbon nanospheres with ultrahigh SSAs, but also offers new materials for the application in energy storage.

\section{Experimental Section}

Materials. The following chemicals were used in the synthesis procedure: aniline (AR, $\geq 99.5 \%$, Shanghai Mackin Biochemical Co. Ltd., China), Ammonium persulfate (AR,98.5 \%,Shanghai Mackin Biochemical Co.,Ltd., China),Triton X-100 (Shanghai Mackin Biochemical Co., Ltd., China), pyrrole (Aladdin Industrial corporation, China) and sublimed sulfur (AR,99.5 \%, Shanghai Mackin Biochemical Co., Ltd., China). All precursors were used as received. 
Synthesis of polyaniline-co-polypyrrole(PACP). HCN-precursor polyaniline-co-

polypyrrole (PACP) hollow spheres were prepared as described in previous papers $\frac{16}{60}$. In a typical case, $3.8 \mathrm{~mL}$ aniline and $2.9 \mathrm{~mL}$ pyrrole were added to $600 \mathrm{~mL}$ deionized water containing $0.6 \mathrm{~g}$ Triton X-100. The mixture was then sonicated and stirred for $30 \mathrm{~min}$ and a homogeneous colorless solution was formed. $19 \mathrm{~g}$ ammonium persulfate (APS) were dissolved to $150 \mathrm{~mL}$ deionized water. The aqueous solution of APS was added to the above mixture and stirred for $1 \mathrm{~min}$, and then polymerized for $12 \mathrm{~h}$ at $0{ }^{\circ} \mathrm{C}$. It is worth noting that the above two reactive mixtures must be pre-cooled to $0^{\circ} \mathrm{C}$ by ice bath. Finally, the PACP were obtained by vacuum-filtering the black product suspension and washing by deionized water until the filtrate is colorless. The obtained PACP was dried in a vacuum oven at $60^{\circ} \mathrm{C}$ for $12 \mathrm{~h}$.

The fabrication of HCN and activated hollow carbon nanospheres (HCN-AC). The HCNs were obtained by carbonizing PACP at different temperature for various times in Ar atmosphere. The resulting $\mathrm{HCNs}$ were denoted as $\mathrm{HCN}-\alpha-\beta \mathrm{H} \gamma \mathrm{R}$, where $\alpha$ refers to the applied carbonization temperatures $\left(800,900,1000^{\circ} \mathrm{C}\right), \beta$ the carbonization hours $(10,20 \mathrm{~h})$ and $\gamma$ the ramp rate of temperature $\left(10^{\circ} \mathrm{C} \mathrm{min}-1\right)$.PACP was firstly carbonized at $800{ }^{\circ} \mathrm{C}$ with $2 \mathrm{~h}$ in $10^{\circ} \mathrm{C} \mathrm{min}{ }^{-1}$. The obtained $\mathrm{HCNs}$ were further heated to $950^{\circ} \mathrm{C}$ under Ar flow $(30$ $\mathrm{mL} \min ^{-1}$ ) with a heating rate of $10{ }^{\circ} \mathrm{C}^{-1}$. When the temperature reached to $950{ }^{\circ} \mathrm{C}$, the $\mathrm{Ar}$ flow was replaced with $\mathrm{CO}_{2}$ flow $\left(30 \mathrm{~mL}^{-1}\right)$ and held for 30,60 , and $90 \mathrm{~min}$, respectively. When started to cool, the $\mathrm{CO}_{2}$ flow was changed back to Ar flow. Finally, the activated HCNs were obtained and named HCNs-AC30, HCNs-AC60, HCNs-AC90, respectively.

Preparations of AC-HCN/S nanocomposite. The obtained HCNs-AC was mixed with sulfur in an agate mortar, ground for $0.5 \mathrm{~h}$. The mixture was then sealed in a glass bottle and heated to $155^{\circ} \mathrm{C}$ at a heating rate of $2{ }^{\circ} \mathrm{C} \mathrm{min}{ }^{-1}$ in an oven, and the temperature was maintained at $155^{\circ} \mathrm{C}$ for $15 \mathrm{~h}$ to ensure complete infiltration of sulfur into HCNs-AC, leading to the formation of HCNs-AC/S composites. According to the difference of SSAs and sulfur content, the composites had been named as HCNs-AC60/S-60, HCNs-AC60/S-75, and HCNs-AC90/S-75.

Characterization. Field emission scanning electron microscope (FESEM) images were captured by using a Hitachi SU-70 FESEM instrument. Transmission electron microscopy (TEM) (JEOL 2011) was utilized to observe sample microstructure. X-ray diffraction (XRD) patterns were recorded on a Bruker D8 advance powder X-ray diffractometer using $\mathrm{Cu}_{\mathrm{K} \alpha}$ radiation. The specific surface areas were determined by the gas sorption technique using a Micromeritics ASAP 2020 based on the Brunauer-Emmett-Teller (BET) method at $77 \mathrm{~K}$. Laser Raman spectroscopy was performed on a Renishaw in Via Spectrometer. 
The fabrication of Li-S batteries and electrochemical measurements. The electrochemical performance of these composites was tested using CR2025 coin-type cells fabricated in an Arfilled glove box $\left(\mathrm{O}_{2}<0.1 \mathrm{ppm} ; \mathrm{H}_{2} \mathrm{O}<0.1 \mathrm{ppm}\right)$. The cathode slurry was prepared by mixing 80 wt. $\%$ of composite, 10 wt. $\%$ of Super-P and 10 wt. \% of PVDF binder in 1-methyl-2pyrrolidinone (NMP). The slurry was blade cast onto carbon-coated aluminum foil and dried at $60{ }^{\circ} \mathrm{C}$ for $12 \mathrm{~h}$ under vacuum. The electrolyte was composed of $1 \mathrm{M}$ bis(trifluoromethane) sulfonimide lithium salt and $0.1 \mathrm{M} \mathrm{LiNO}_{3}$ in a mixture of 1,3-dioxolane and 1,2dimethoxyethane (1:1 by volume). The charge-discharge tests were conducted on NEWARE (Shenzhen, China) instruments (model $5 \mathrm{~V}-10 \mathrm{~mA}$ ) with voltage window of $\approx 1.5-2.6 \mathrm{~V}$ versus $\mathrm{Li}^{+} / \mathrm{Li}$. The area loading of sulfur is about $1.5-2.0 \mathrm{mg} \mathrm{cm}^{-2}$ in a cell and the amount of electrolyte is $20 \mathrm{uL} \mathrm{m}^{-} \mathrm{S}$. Cyclic voltammetry (CV) experiments were performed on a $\mathrm{CHI}$ $660 \mathrm{E}$ (Shanghai, China) electrochemical workstation at a scan rate of $0.1 \mathrm{mV} \mathrm{s}^{-1}$ from 2.9 to $1.6 \mathrm{~V}$. The EIS is performed at open circuit voltage $(\approx 2.6-3.0 \mathrm{~V})$ when the lithium anode is not passivated by the polysulfides. Moreover, the frequency range is from $10^{5}$ to $0.05 \mathrm{~Hz}$ and the perturbation amplitude was $5 \mathrm{mV}$.

\section{Acknowledgements}

This work was financially supported by the National Natural Science Foundation of China (Nos.51202150, 51272161,21703141), Program of Introducing Innovative Research Team in Dongguan (No.2014607109), foundation of the State Key Laboratory of Solidification Processing in NWPU(SKLSP201110), Shenzhen Basic Research Program (No. JCYJ20160422091418366) and foundation of Shenzhen University Innovation and Development (PIDFP-ZR2017022).

\section{Conflict of interest}

The authors declare no conflict of interest.

\section{References}

[1] Y. W. Ju, G. R. Choi, H. R. Jung, W. J. Lee, Electrochim. Acta 2008, 53, 5796-5803.

[2] Z. Wang, D. Luan, S. Madhavi,Y.Hu, X. W. Lou, Energy Environmental Sci. 2012, 5,52525256.

[3] F. Sun,J.H.Gao, X. X. Pi, L. J. Wang, Y. Q. Yang, Z. B. Qu, S. H. Wu, J. Power Sources 2017, 337,189-196.

[4] W. Gu,G.Y ushin, Wiley Interdisciplinary Reviews Energy\&Environment 2014, 3,424473; Environment 2014,3,424-473.

[5] N. Brun, K. Sakaushi, L. Yu,L.Giebeler,J.Eckert, M. M. Titirici, Phys. Chem. Chem. Phys. 2013, 15,6080-6087. 
[6] Y. Yao, H. Wu, L. Huang, X. Li, L. Yu,S.Zeng, X. Zeng, J. Yang,J.Zou, Electrochim. Acta 2017, 246,606-614.

[7] H. Xu, J. Guo, K. S. Suslick, Adv.Mater. 2012, 24,6114-6114.

[8] Z. J. Yi,G.Chao, K. H. Wen, Y. Zhu, A. Huczko, M. Bystrzejewski, M. Roe, Y. L. Chi, S. Acquah, H. Kroto, Carbon 2005, 43,2685.

[9] J. Liu, N. P. Wickramaratne, S. Z. Qiao, M. Jaroniec, Nat. Mater. 2015, 14, 763-774.

[10] W. Meier, Chem. Soc. Rev. 2000, 29,295-303.

[11] J. Liu, F. Fan, Z. Feng, L. Zhang,S.Bai, Q. Yang, C. Li, J. Phys. Chem.C 2008, $112,16445-16451$.

[12] Q.-F.L e,Z.-W.H e, J.-Y.Zhang, Q. Lin, J. Anal. Appl. Pyrolysis 2012, 93, 147-152.

[13] Y. H. Ng, S. Ikeda, T. Harada, S. Higashida,T.Sakata, H. Mori,M.Matsumura, Adv. Mater. 2007, 19,597-601.

[14] K. Tang,L.Fu, R. J. White, L. Yu,M.M.Titirici, M. Antonietti, J. Maier, Adv. Energy Mater. 2012, 2,873-877.

[15] F. D. Han, Y. J. Bai, R. Liu, B. Yao, Y. X. Qi, N. Lun, J. X. Zhang, Adv.Energy Mater. 2011, 1,798-801.

[16] F. Xu, Z. Tang, S. Huang, L. Chen,Y.L iang, W. Mai, H. Zhong,R.F u, D. Wu, Nat. Commun. 2015, 6,7221.

[17] P. G. Bruce, S. A. Freunberger,L.J.Hardwick, J. M. Tarascon, Nat. Mater. 2012, 11,1921.

[18] Y. Yang, G. Zheng, Y. Cui, Cheminform 2013, 44,no-no.

[19] Y. X. Yin, S. Xin, Y. G. Guo, L. J. Wan, Angew.Chem. Int. Ed. 2013, 52, 13186; Angew.Chem. 2013, 125,13426-13441.

[20] A. Eftekhari, D.-W.Kim, J. Mater.Chem. A 2017, 5,17734-17776.

[21] Z. Li, H. B. Wu, X. W. Lou, Energy Environ. Sci. 2016, 9,3061-3070.

[22] A. Manthiram, Y. Fu, S. H. Chung, C. Zu, Y. S. Su, Chem. Rev. 2014, 114, 11751.

[23] X. Ji, K. T. Lee, L. F. Nazar, Nat. Mater. 2009, 8,500-506.

[24] A. Manthiram, S. H. Chung, C. Zu, Adv. Mater. 2015, 27,1980-2006.

[25] Z. Li, B. Y. Guan, J. Zhang, X. W. Lou, Joule 2017, 1,576-587.

[26] S. Rehman, K. Khan, y. zhao, Y. Hou, J. Mater. Chem. A 2017, 5,3014- 3038.

[27] O. Ogoke, G. Wu, X. Wang, A. Casimir,L.Ma, T. Wu, J. Lu, J. Mater.Chem. A 2017, $5,448-469$.

[28] M. Liu, X. Qin, Y. He, B. Li, F. Kang, J. Mater. Chem. A, 2017, 5,5222- 5234.

[29] Z. Li, J. Zhang, B. Guan, D. Wang, L.-M. Liu, X. W. Lou, Nat. Commun. 2016, 7,13065. 
[30] C. Q. Zhou, J. Han,G.P.Song, R. Guo, J. Polymer Science Part A-Polymer Chemistry 2008, 46,3563-3572.

[31] W. Xia, A. Mahmood, R. Zou, Q. Xu, EnergyEnviron. Sci. 2015, 8,1837- 1866.

[32] H. Furukawa, K. E. Cordova, M. O’Keeffe, O. M. Yaghi, Science 2013, 341, 974.

[33] W. Xia, B. Qiu, D. Xia, R. Zou, Sci. Rep. 2013, 3,1935.

[34] S. Gadipelli, Z. X. Guo, ChemSusChem 2015, 8,2123-2132.

[35] M. Klose, R. Reinhold, K. Pinkert, M. Uhlemann, F. Wolke,J.Balach, T. Jaumann, U. Stoeck, J. Eckert, L. Giebeler, Carbon 2016, 106,306-313.

[36] C. Hu, S. Sedghi, S. H. Madani, A. Silvestre-Albero, H. Sakamoto, P. Kwong, P. Pendleton, R. J. Smernik, F. Rodr\&guez-Reinoso, K. Kaneko, M. J. Biggs, Carbon 2014, $78,113-120$.

[37] R. Qiang, Y. Du, Y. Wang, N. Wang, C. Tian, J. Ma, P. Xu, X. Han, Carbon 2016, 98,599606.

[38] F. Tuinstra, J. L. Koenig, J. Chem. Phys. 1970, 53,1126-1130.

[39] R. J. Nemanich, S. A. Solin, R. M. Martin, Phys. Rev.BCondensedMatter 1981, 23,63486356.

[40] H. Luo, Y. Yang, B. Mu, Y. Chen,J.Zhang, X. Zhao, Carbon 2016, 100, 214-222.

[41] X. Y. Yang, J. J. Xu, D. Bao, Z. W. Chang, D.P.Liu, Y. Zhang, X. B. Zhang, Adv.Mater. 2017, 29,1700378.

[42] A. C. Ferrari, Nat. Nanotechnol. 2013, 8,235-246.

[43] R. Demir-Cakan, M. Morcrette, F. Nouar,C.Davoisne,T.Devic, D. Gonbeau, R. Dominko, C. Serre, G. F8rey,J.M.Tarascon, J. Am. Chem. Soc. 2011, 133,16154-16160.

[44] J. J. Xu, Z. W. Chang, Y. B. Yin, X. B. Zhang, ACS Cent. Sci. 2017, 3,598- 604.

[45] A. T. Ward, J. Phys. Chem. 1968, 72,4133-4139.

[46] H. Wang,C.Zhang, Z. Chen,H.K.Liu, Z. Guo, Carbon 2015, 81,782- 787.

[47] H.-J. Peng, T.-Z. Hou, Q. Zhang,J.-Q. Huang, X.-B. Cheng, M.-Q. Guo, Z. Yuan, L.-Y.He, F. Wei, Adv.Mater.Interf. 2014, 1,1400227.

[48] L.-C. Yin, J. Liang, G.-M.Zhou,F.L i, R. Saito, H.-M. Cheng, Nano Energy 2016, 25,203210.

[49] T. Z. Hou, X. Chen,H.J.Peng, J. Q. Huang,B.Q.L i, Q. Zhang,B.L i, Small 2016, 12,32833291.

[50] Y. Liu, J. Guo, J. Zhang, Q. Su, G. Du, Appl. Surf. Sci. 2015, 324,399-404.

[51] N. Jayaprakash, J. Shen,S.S.Moganty, A. Corona, L. A. Archer, Angew. Chem. Int. Ed. 2011, 50,5904-5908. 
[52] S.-Z. Zeng, Y. Yao, X. Zeng,Q.H e, X. Zheng,S.Chen,W.T u, J. Zou, J. Power Sources 2017, 357,11-18.

[53] Y. Wu, M. Gao, X. Li, Y. Liu, H. Pan, J. Alloysand Compounds 2014, 608, 220-228.

[54] S. Wang, T. Sun, S. Yuan, Y.-h. Zhu, X.-b. Zhang, J.-m. Yan, Q. Jiang, Mater.Horiz. 2017, 4,1122-1127.

[55] C. N. Lin, W. C. Chen,Y.F.Song, C. C. Wang, L. D. Tsai, N. L. Wu, J. Power Sources 2014, 263,98-103.

[56] Z. Wei Seh,W.L i, J. J. Cha, G. Zheng, Y. Yang,M.T.McDowell, P. C. Hsu, Y. Cui, Nat. Commun. 2013, 4,1331.

[57] S. Chen, X. Huang, H. Liu, B. Sun,W.Yeoh, K. Li, J. Zhang,G.Wang, Adv. Energy Mater. $2014,4,1301761$.

[58] J. J. Xu, Q. C. Liu, Y. Yu,J.Wang, J. M. Yan, X. B. Zhang, Adv. Mater. 2017, 29,1606552. [59] J.-J. Xu, X.-B. Zhang, Nat. Energy 2017, 2,17133.

[60] W. Li, Q. Zhang, G. Zheng, Z. W. Seh, H. Yao, Y. Cui, Nano Lett. 2013, 13, 5534-5540.

[61] J.-L. Ma,D.Bao, M.-M. Shi,J.-M. Yan, X.-B. Zhang, Chem. 2017, 2,525- 532.

[62] J. Zang, T. An, Y. Dong, X. Fang, M. Zheng, Q. Dong, N. Zheng, Nano Res. 2015, 8,26632675.

[63] F. Wu, J. Li, Y. Su, J. Wang, W. Yang, N. Li, L. Chen, S. Chen,R.Chen,L . Bao, Nano Lett. 2016, 16,5488-5494.

[64] X. Zhao, D.-S. Kim, H.-J. Ahn, K.-W.Kim, K.-K.Cho, J.-H. Ahn, Mater. Res. Bull. 2014, 58,204-207.

[65] L. Zhu, H.-J. Peng, J. Liang, J.-Q. Huang,C.-M.Chen,X.Guo, W. Zhu, P. Li, Q. Zhang, Nano Energy 2015, 11,746-755.

[66] G. Zhou,Y.Zhao, A. Manthiram, Adv.Energy Mater. 2015, 5,1402263.

[67] M. Zhang, C. Yu,C.Zhao, X. Song,X.Han, S. Liu, C. Hao, J. Qiu, Energy Storage Mater. 2016, 5,223-229. 
2017-12-13

\section{Facile synthesis of}

ultrahigh-surface-area hollow carbon nanospheres and their application in lithium-sulfur batteries

\section{Zeng, Shao-Zhong}

Wiley-VCH

Zeng SZ, Yao Y, Huang L, et al., (2018) Facile synthesis of ultrahigh-surface-area hollow carbon nanospheres and their application in lithium-sulfur batteries. Chemistry - A European journal, Volume 24, Issue 8, February 2018, pp. 1988-1997

https://doi.org/10.1002/chem.201705211

Downloaded from Cranfield Library Services E-Repository 